\title{
PAGES international course: South American climatology and quantitative high-resolution climate reconstructions in Palaeoecology
}

\section{Valdivia, Chile, 23-27 October 2010}

Marcela Tonello ${ }^{1}$ and Antonio Maldonado ${ }^{2}$

'Department of Biology, University of Mar del Plata, Argentina; mtonello@mdp.edu.ar

${ }^{2}$ Laboratory of Palaecology, Centre for Advanced Studies in Arid Zones, La Serena, Chile

This educational course on quantitative paleoecology and South American climatology was organized as a pre-conference event prior to a major international PAGES symposium in Valdivia (see below). The objective of this course was to impart a high level of first-hand knowledge to early career researchers from Latin American countries working in paleoecology and paleoclimatology. The course topics had been selected on the basis of students' enquires that followed the "International Workshop on Methods in Quaternary Palaeoecology" held in La Serena in 2007 (Maldonado and Latorre, 2008).

A total of 27 participants from Argentina (11), Chile (8), Brazil (3), Colombia (2), Switzerland (2) and Bolivia (1) were chosen from over 70 applicants. All participants were graduate students or young post-doctoral scientists working with a variety of different paleo-proxies (pollen, diatoms, tree rings, plant macrofossils, etc.) on projects across South America (Fig. 1).

The lectures on the first three days of the course were given by Prof. John Birks (University of Bergen) on quantitative paleoecology and environmental reconstructions, including an overview of the major numerical methods such as ordination analysis, analysis of stratigraphical data, data calibration and transfer functions. The last two days, Prof. René Garreaud (University of Chile) gave a presentation on South American climatology including the basic climate dynamics, the fundamental statistical tools applied in climatology and the general concepts of South American climate. After the lectures, the participants had the opportunity to discuss their own data with the lecturers and immediately apply their newly acquired knowledge.

Given that the course topics were highly relevant to the general PAGES objectives, all participants also attended the II International Symposium "Reconstructing Climate Variations in South America and the Antarctic Peninsula over the last 2000 years" (LOTRED-SA) the following week. At the LOTRED-SA conference, they

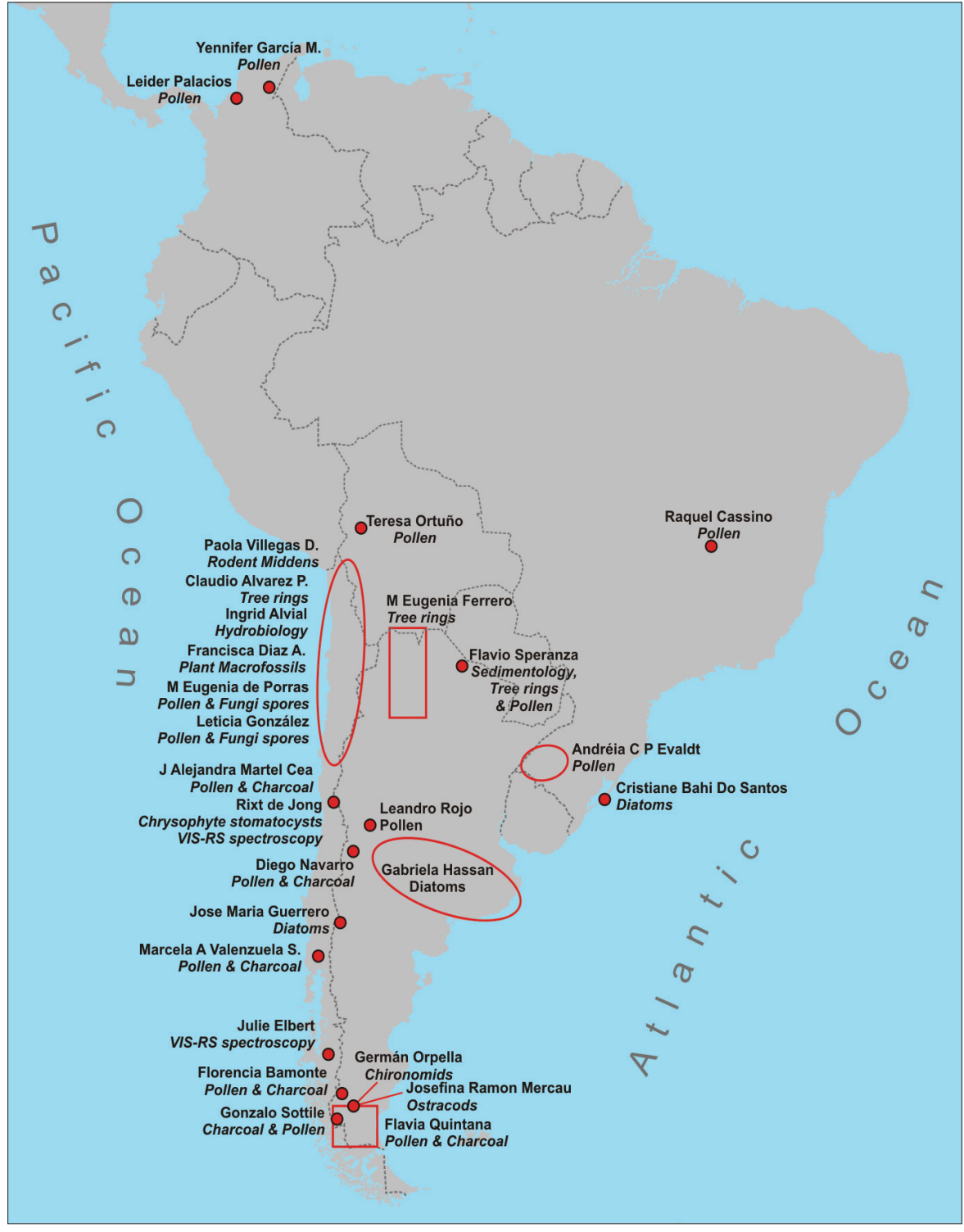

Figure 1: Twenty-seven participants from Argentina, Chile, Brazil, Colombia, Switzerland and Bolivia attended the workshop. Their research areas and used proxies are indicated in the map above.

met experienced researchers working on different projects in South America and had the opportunity to exchange and discuss ideas with them.

Initiatives like this PAGES supported educational meeting, offer emerging South American researchers the chance to gain access to the finest knowledge and expertise.

The conveners wish to thank Prof. John Birks and Prof. René Garreaud for their willingness to deliver the course and PAGES, University of La Serena, Centre for Advanced Studies in Arid Zones (CEAZA),
Southern University of Chile (UACh) and Center for Scientific Studies (CECS) for financial and logistical support.

\section{References}

Maldonado, A. and Latorre, C., 2008: International Workshop on Methods in Quaternary Paleoecology, PAGES News, 16: 38. 